\title{
Fermentation and in vitro gas production of high pressure steam treated sugarcane pith by rumen fungi
}

M Chaji, T Mohammadabadi, M Eslami

Ramin (Khozestan) Agricultural and Natural Resources University, Mlassani,Khozestan/Ahvaz, Islamic Republic of Iran Email: morteza34312002@yahoo.co.uk

Introduction Gas production technique is a useful procedure to assess digestible value of the ruminant feeds. Sugarcane pith is a by-product of the final stage of the processing of sugarcane as it passes through rotary sieves to separate fine particles. Steam explosion has shown considerable potential as a method for the cost-effective pre-treatment of lignocellulosic material. At the end of this process, a substantial proportion of the hemicellulose fraction is made water soluble and the lignin fraction is modified to improve enzymatic accessibility and digestibility. By applying the steam explosion process to sugarcane bagasse, Kling et al. (1987) demonstrated that about $60 \%$ of the hemicellulose fraction was hydrolysed and the susceptibility of cellulose to enzymatic hydrolysis was increased. For treatments by steam, harsh conditions are needed $\left(\mathrm{t}>180^{\circ} \mathrm{C}\right)$, these conditions result in formation of furfural by secondary dehydration reactions of hemicellulosic pentoses and soluble phenolic compounds, which may inhibit the activity of rumen microbes and cell-free enzymes. If the high pressure steam treatment had negative effects on activity of rumen microbes particularly fungi (rumen fungi are as primary colonizers of fibrous plant materials that degrade lignin-containing plant cell walls, and the ability of anaerobic fungi to degrade and utilize lignin would be an important attribute for rumen micro-organisms), the steamprocessing industries of sugarcane pith should correct their processing method. Therefore, the objective of this study was to evaluate the effect of high pressure steam on the gas production parameters of sugarcane pith by rumen fungi during in vitro fermentation.

Material and methods The experimental samples were: untreated sugarcane pith (USP) or steam treated sugarcane pith (SSP), (at 19 bar for $3 \mathrm{~min}, 70 \%$ moisture). About $200 \pm 10 \mathrm{mg}$ of oven dried and milled sample (1.0 mm screen) was incubated with $35 \mathrm{ml}$ buffered rumen fungi in $100 \mathrm{ml}$ glass syringes, according to the method of Menke and Steingass (1988). To prepare anaerobic rumen fungi, rumen fluid was collected from two fistulated Holstein steers $(400 \pm 12 \mathrm{Kg}$, body weight) fed twice daily a diet containing $5.72 \mathrm{~kg}$ lucerne hay and $3.08 \mathrm{~kg}$ concentrate mixture, then centrifuged (1000 rpm, $10 \mathrm{~min})$ and streptomycin sulphate, penicillin $\mathrm{G}$ and chloramphenicol added $(0.1 \mathrm{mg} / \mathrm{ml}$ each). All samples were incubated in triplicate (one run) with three syringes containing only incubation medium (blank) and gas production from the sample was corrected for the blank. Gas production was measured at 2, 4, 6, 8, 12, 24, 48, 72 and 96 h. Cumulative gas production data were fitted to the exponential equation $\mathrm{Y}=\mathrm{B}\left(1-\mathrm{e}^{-\mathrm{ct}}\right)$, where $\mathrm{B}$ is the gas production from the fermentable fraction $(\mathrm{ml})$, $\mathrm{C}$ is the gas production rate constant for $\mathrm{B}, \mathrm{t}$ is the incubation time $(\mathrm{h})$ and $\mathrm{Y}$ is the gas produced at time $\mathrm{t}$. In vitro digestibility of organic matter (OMD, $\mathrm{g} / \mathrm{kg} \mathrm{OM}$ ) of samples was calculated by the equation of Menke and Steingass (1988). Microbial biomass (MB) production was estimated by method of Blummel et al. (1997). Data of gas production parameters, OMD and MB were analyzed as a completely randomized design using the General Linear Model (GLM) procedure of SAS (1990). Duncan's multiple range tests was used to compare treatment means at $\mathrm{P}<0.05$.

Results In vitro gas production parameters [(B) and (C)], OMD and MB of the samples by rumen fungi are shown in Table 1. All items were significantly influenced by the treatment. Gas production parameters of SP were significantly higher than UP $(\mathrm{P}<0.01)$. Steam resulted in increase OMD compared with the untreated samples $(175.5 v s .158 .2 \mathrm{ml}$ per $200 \mathrm{mg} \mathrm{DM})$. Value of MB was decreased when sugarcane pith was treated with steam.

Table 1 In vitro gas production parameters, OMD and MB of steam treated (STP) sugarcane pith by rumen fungi

\begin{tabular}{lllll}
\hline \hline & USP & SSP & s.e.m & P \\
\hline B (ml) & $29.5^{\mathrm{b}}$ & $45.6^{\mathrm{a}}$ & 0.51 & $<.0001$ \\
$\mathrm{C}(\mathrm{ml} / \mathrm{h})$ & $0.02^{\mathrm{b}}$ & $0.03^{\mathrm{a}}$ & 0.003 & $<.0001$ \\
$\mathrm{OMD}(\mathrm{g} / \mathrm{kg} \mathrm{OM})$ & $158.2^{\mathrm{b}}$ & $175.5^{\mathrm{a}}$ & 0.006 & $<.0001$ \\
$\mathrm{MB}(\mathrm{mg} / \mathrm{g})$ & $62.3^{\mathrm{a}}$ & $49.1^{\mathrm{b}}$ & 0.51 & $<.0001$ \\
\hline \hline
\end{tabular}

UP: Sugarcane pith untreated; SP: Steam treated sugarcane pith, B: Gas production from the fermentable fraction; C: Rate constant of gas production; OMD: Organic matter digestibility; MB: Microbial biomass; s.e.m: Standard error of mean, Means with different letters within samples differed $(\mathrm{P}<0.05)$

Conclusions It was concluded that in vitro gas production parameters, OMD and MB of sugarcane pith treated with highpressure steam by anaerobic rumen fungi were improved compared with the untreated samples. The results of the present study indicated that use of high-pressure steam for treatment of sugarcane pith, solubilised the hemicellulose fraction which resulted in improved fermentation and gas production, as well as had no negative effect on rumen fungi.

\section{References}

Blummel, M., Makkar, H.P.S., and Becker, K. 1997. Journal of Animal Physiology and Animal Nutrition. 77, $24-34$.

Kling, S.H., Carvalho-Neto, C., Ferrara, M.A., Torres, J.C.R., Magalhaes, D.B., and Ryu, D.D.Y. 1987. Biotechnology and Bioengineering. 29, 1035-1039.

Menke, K.H. and Steingass, H. 1988. Animal Research Development. 28, 7-55. 